\title{
Advance the stability of the vehicle by using the pneumatic suspension system integrated with the hydraulic actuator
}

\author{
Tuan Anh Nguyena* (D) \\ ${ }^{a}$ Automotive Engineering Department, Thuyloi University, 175 Tay Son, Dong Da, Hanoi, Vietnam. Email: anhngtu@tlu.edu.vn \\ *Corresponding author
}

https://doi.org/10.1590/1679-78256621

\begin{abstract}
The stability and comfort of vehicles depend on the operation of the suspension system. To increase the smoothness and comfort for passengers in the vehicle, the stiffness of the suspension system needs to be changed flexibly. The conventional pneumatic suspension system can partially meet these requirements. However, the change is not much. This paper introduces a model of the pneumatic suspension system integrated with a hydraulic actuator. This is a completely novel and unique method. In the case that the excitation is random, average values of displacement and acceleration of the sprung mass are only $12.56(\mathrm{~mm})$ and $3.78\left(\mathrm{~m} / \mathrm{s}^{2}\right)$ if the vehicle uses the integrated pneumatic suspension system. In contrast, this value is very large, up to $30.70(\mathrm{~mm})$ and $6.53\left(\mathrm{~m} / \mathrm{s}^{2}\right)$ if the passive suspension system is used. Similarly, this change is also very large in the remaining survey situations. Overall, the values of acceleration and displacement of the sprung mass are significantly reduced when the vehicle is equipped with an integrated pneumatic suspension system. The results of the research showed the advantages of this method compared to other methods.
\end{abstract}

\section{Keywords}

Pneumatic suspension system, hydraulic actuator, integrated suspension, comfort, stability

\section{Graphical Abstract}
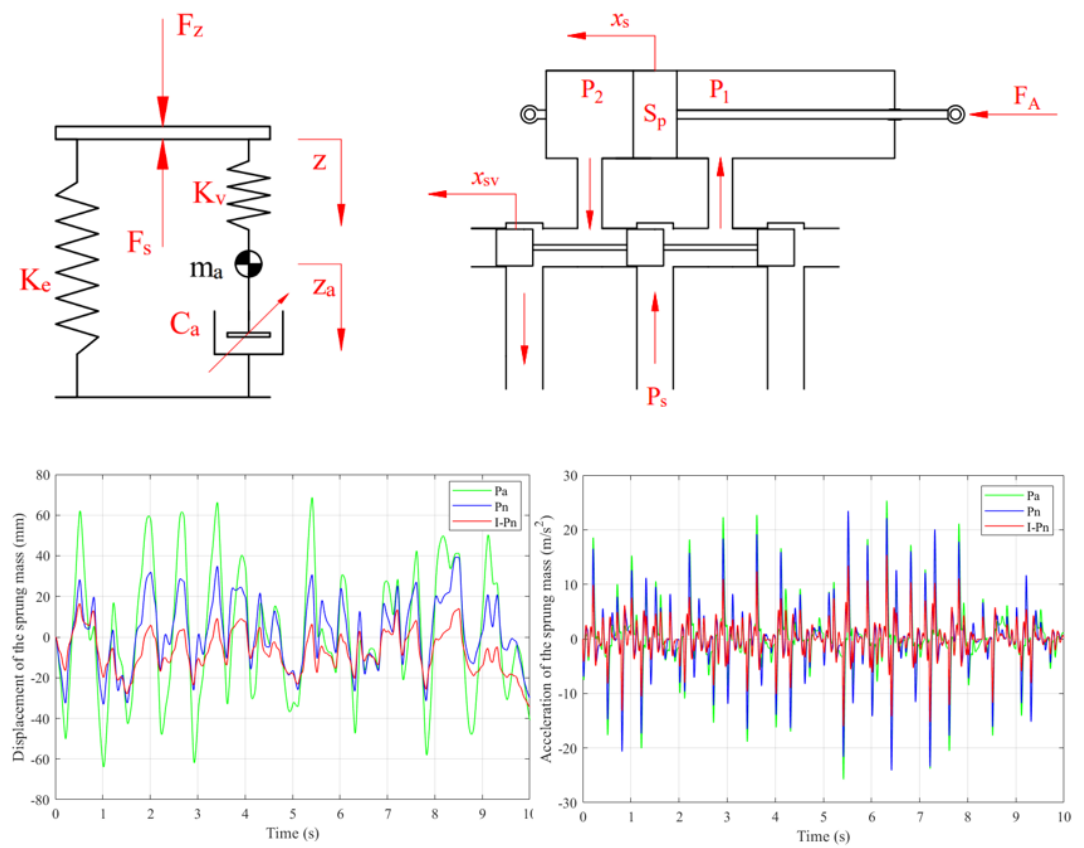

Received June 20, 2021. In revised form September 14, 2021. Accepted September 18, 2021. Available online September 20, 2021 https://doi.org/10.1590/1679-78256621

(a) Latin American Journal of Solids and Structures. ISSN 1679-7825. Copyright (C) 2021. This is an Open Access article distributed under the terms of the Creative Commons Attribution License, which permits unrestricted use, distribution, and reproduction in any medium, provided the original work is properly cited. 


\section{INTRODUCTION}

The vibration of the vehicle when moving on the road is one of the extremely important issues. Oscillation usually occurs when there is an external stimulus. To quell these oscillations, the suspension system is fitted on all models today. The syspension system separates the vehicle into two completely separate parts, including the sprung mass and the unsprung mass. All the components above the suspension system (passengers, cargoes, etc.) are called the sprung mass. It takes up most of the vehicle's total mass. In contrast, the components below the suspension system (wheels, axles, brakes, etc.) are assumed to be unsprung mass [1]. The optimal division of these two values is extremely important, it helps to control the oscillations properly.

Normally, the suspension system consists of three parts: spring, damper, and lever arm. For the conventional passive suspension system, the stiffness of the spring and damper is constant. As a result, the stability and comfort of the vehicle can be greatly affected. In order to improve this problem, it is necessary to change the characteristics of the spring and damper, or both. The method of using the semi-active suspension system (changing the damping stiffness) has been introduced and equipped on some models $[2,3]$. However, this method can only help the vehicle to partially extinguish the vertical vibration. It is not able to guarantee stability in other cases. The improvement of the suspension system's smoothness through changing the stiffness of the spring is appreciated. The conventional metal spring will be replaced by the pneumatic spring, which can control stiffness through internal pneumatic pressure [4]. The pneumatic suspension system is often equipped on high-end vehicles or large passenger vehicles, its price is very expensive.

The pneumatic suspension system model has been studied in recent years. Characteristics of the pneumatic suspension system were introduced and analyzed in [5]. According to Yin et al., the pneumatic suspension system has a direct effect on the stiffness and height of the vehicle [6]. These problems are again exemplified by Eskandary et al. based on their paper [7]. Various models of the pneumatic suspension system have been used such as the Nishimura model, the VAMPIRE model, the SIMPAC model, and the GENSYS model. In which, GENSYS model is the novel model and it is appreciated [8]. In [9], Gavriloski et al. used this model for their paper. Besides, Moheyeldein et al. also evaluated the effectiveness of the GENSYS model in their research [10]. In addition, a nonlinear dynamic model of pneumatic spring with damper has also been introduced by Zhu et al. [11]. Similarly, the pneumatic suspension model used novel damper has also been proposed by Xiao et al. They have come up with an optimal control algorithm PID for the system [12].

The pneumatic suspension system is not only used in passenger vehicles, but it is also widely used on special vehicles. According to [13], the pneumatic suspension system has been mounted in the hub of the electric vehicle, which uses the motor in-wheel. Therefore, the structure of the vehicle is very compact. However, it still meets the requirements of the vehicle's stability and safety. On agricultural vehicles, the pneumatic suspension system has also been equipped, which achieves very high performance [14]. In addition, the pneumatic suspension system can be integrated with the energy harvesting system that is found on some special models. It can provide optimum efficiency in terms of energy when the vehicle oscillates [15]. Further, the hydropneumatic suspension system has been equipped on many specialized vehicles such as trains, tanks, soil compactor, etc. to improve the vibration efficiency of the vehicle [16-19]. Overall, this system can meet the vehicle's stability requirements well.

When the vehicle is equipped with a pneumatic suspension system, the vehicle's vibrations are better controlled than with a conventional passive suspension system [20]. This has also been demonstrated experimentally by Kumbhar et al. [21]. The pneumatic suspension system can also be supposed as a form of the active suspension system. Therefore, control methods for the active suspension system are proposed to be used for the pneumatic suspension system. If the system is considered to be linear, PID and LQR control methods can be applied. In [22], Anh compared the effectiveness of these two methods. When the LQR controller is combined with the Gaussian filter, it becomes the LQG controller [23]. Besides, many nonlinear and intelligent control methods for the suspension system have also been proposed. In [24], Zhao et al. introduced a robust control method for the pneumatic suspension system. This method helps the height of the vehicle body to be controlled stably, the input parameters can be changed continuously. Compared with conventional linear control methods, this method helps the vehicle oscillation approach the desired threshold. In addition, robust control methods for the active suspension system can also be applied to pneumatic suspension systems $[25,26]$. In [27], Nieto et al. controlled the active suspension system by the adaptive control method. This method was again used in the study of Fu et al. According to [28], the displacement and the acceleration of the sprung mass are almost unchanged even though the sprung mass changes continuously. Besides, intelligent and integrated control methods have also been proposed. In [29], Rui introduced a nonlinear adaptive sliding mode controller for a pneumatic suspension system. This is a combination of two nonlinear control methods. The tracking nonlinear controller was also used in the paper of Zhao et al. [30]. The predictive control model for the pneumatic suspension system has also been used, the effect of which is extremely positive [31]. The sliding mode control method has also been 
shown in the studies of Chen et al. and Zhou et al. [32, 33]. Besides, other control methods for the active suspension system that have been highly effective can also be applied to the pneumatic suspension system [34-39].

The pneumatic suspension system helps to improve the vehicle's stability and safety when moving on the road. However, this improvement is not much. In many cases, the stability and comfort of the vehicle are still not guaranteed. Therefore, this paper has proposed the use of the pneumatic suspension system, which is integrated with a hydraulic actuator to improve comfort and smoothness. The actuator used in this research is a hydraulic piston, which is widely used on mechatronics systems. According to [40], the hydraulic piston operates based on the opening and closing of the valve of the servo valve system. The fluid in the system is conveyed by the hydraulic pump. In [41], Lee et al. introduced a new method to control the operation of the hydraulic pump. The opening and closing of the actuator's valves are controlled based on the voltage signal that is sent from the controller. Shafie et al. developed an algorithm to control the hydraulic actuator, they used two PID controllers for each hydraulic piston [42]. According to [43], the efficiency of the actuator can be improved by using the sliding mode controller. Similarly, this method has also been mentioned in the paper of Sam and Osman [44]. In addition, integrated controllers have also been introduced to control the operation of hydraulic actuators [45]. In general, the above control methods bring positive effects to the system.

Previous studies on the pneumatic suspension system often only mentioned the use of the independent pneumatic suspension system. This does not solve the vehicle's vibration problems. Therefore, this paper proposes the use of the pneumatic suspension system that integrates a hydraulic actuator to improve the stability and comfort of the vehicle when moving on the road. The combination of the pneumatic spring and the hydraulic actuator is a novel and unique solution. They can operate independently from each other. Besides, they can also support each other. It enhances the vehicle's safety and comfort more than other conventional solutions. This research analyzes, simulates, and evaluates the efficiency of the integrated pneumatic suspension system. Simulation is performed in the Matlab-Simulink environment. The method and control model are detailed in the content below.

\section{MATERIAL AND METHOD}

\subsection{Pneumatic Suspension Model}

The physical model of the pneumatic spring is given as shown in Figure 1. Equation (1) shows the balance of the force acting on the pneumatic spring.

$$
F_{z}=A_{e} p_{b}=A_{e}\left(p_{0}-p_{a t}\right)
$$

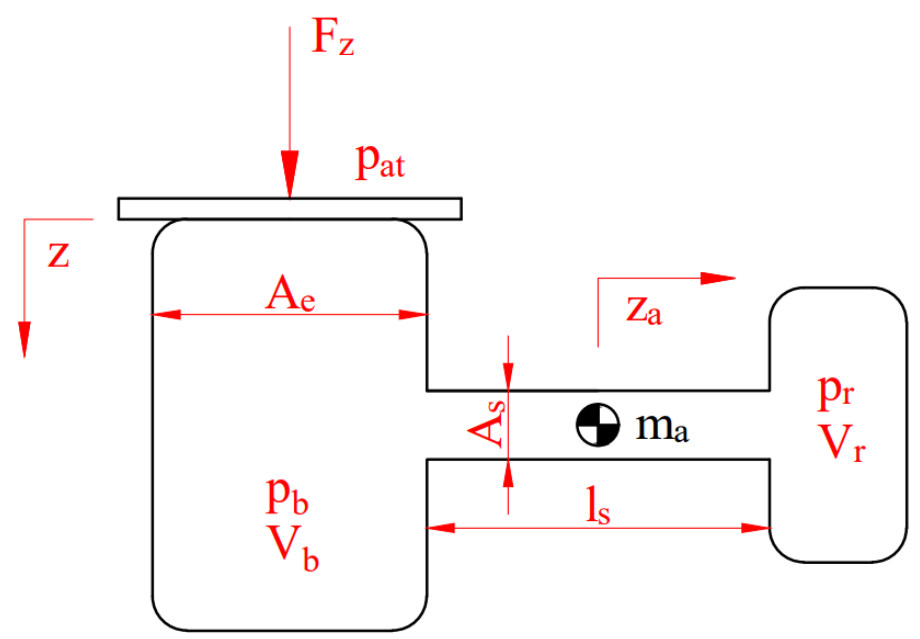

Figure 1 The physical model of the pneumatic spring.

When the spring is subjected to a static load $F_{z}$, the pressure between the two chambers changes. Therefore, the force $F_{p}$ appears, which pushes the gas's mass to move along the pipe. As this mass moves, it generates a frictional force $\mathrm{F}_{\mathrm{f}}$, which is a nonlinear frictional force. This shift is described through equation (2):

$m_{a} \ddot{z}_{a}=F_{p}-F_{f}=\left(p_{b}-p_{r}\right) A_{s}-C_{a} \dot{z}_{a}^{2}$ 
Based on this principle, many dynamic models of pneumatic springs have been proposed. In this paper, the GENSYS model is used. This is a novel model, and it has high accuracy and is suitable for the vibration simulation problems of the vehicle [8].

The pneumatic spring is converted equivalently to the oscillating system in Figure 2 . This system consists of the main spring $\mathrm{K}_{\mathrm{e}}$, the auxiliary spring $\mathrm{K}_{\mathrm{v}}$, these are two linear springs. The compressed air in the spring is converted to mass ma. As air moves through the pipes, they create friction. This friction process is shown through $\mathrm{C}_{\mathrm{a}}$ nonlinear damping.

The stiffness of the main spring $K_{e}$ depends on the initial absolute pressure $p_{0}$, the effective area of the spring $A_{e}$, the initial volumes of the balloon and reservoir $V_{b 0}$ and $V_{r 0}$, and multivariable coefficient $n$.

$$
K_{e}=\frac{p_{0} n A_{e}^{2}}{V_{b 0}+V_{r 0}}
$$

The stiffness of the auxiliary spring $K_{v}$ is proportional to the stiffness of the main spring $K_{e}$ through the ratio between the initial volumes.

$$
K_{v}=\frac{p_{0} n A_{e}^{2}}{V_{r 0}+V_{b 0}} \frac{V_{r 0}}{V_{b 0}}=K_{e} \frac{V_{r 0}}{V_{b 0}}
$$

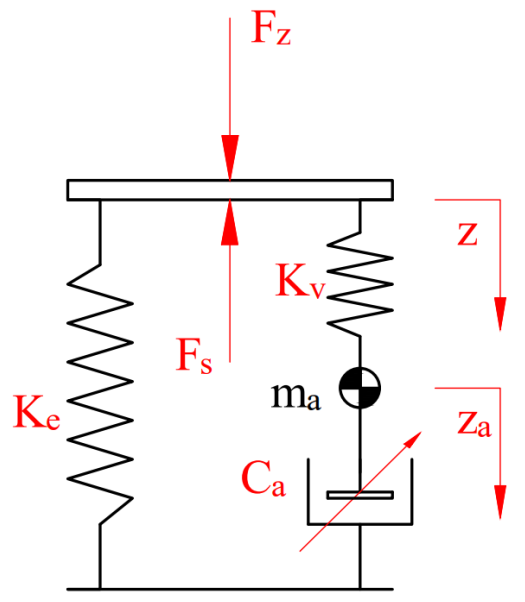

Figure 2 GENSYS model.

To simplify the model, the compressed air is equivalently converted to mass $\mathrm{m}_{\mathrm{a}}$. This is a nonlinear function, and it depends on the characteristics of the air and the size of the pneumatic spring.

$m_{a}=\rho A_{s} l_{s}\left(\frac{A_{e}}{A_{s}} \frac{V_{r 0}}{V_{r 0}+V_{b 0}}\right)^{2}$

The damping coefficient $C_{a}$ of the pneumatic spring is nonlinear. In order to calculate this value, the parameters of the size of the spring $A_{e}$, the size of the pipe $A_{s}$, the initial volume of balloon and reservoir $V_{r 0}, V_{b 0}$, the density of the air $\rho$, and the total loss coefficient of the connection pipes $k$ need to be determined before.

$C_{a}=\frac{1}{2} A_{s} \rho k\left(\frac{A_{e}}{A_{s}} \frac{V_{r 0}}{V_{r 0}+V_{b 0}}\right)^{1+b}$

After the necessary coefficients have been determined, the vehicle dynamics model can be established. In the oscillation and control problems of vehicles, the quarter dynamic model is often used (Figure 3). This model consists of the linear damper $C$, the pneumatic spring $\left(K_{e}, K_{v}, C_{a}\right)$, and the hydraulic actuator $A$. Instead of the usual two degrees of 
freedom, this model uses three degrees of freedom $\left(z_{1}, z_{2}\right.$, and $\left.z_{a}\right)$. The vehicle's oscillation is generated from the excitation from the road surface $h$.

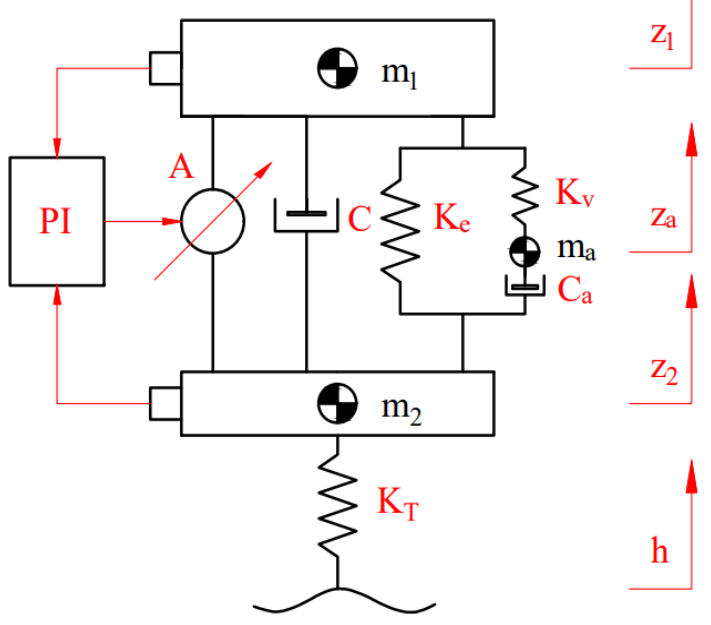

Figure 3 The quarter dynamic model.

The vertical displacement of the sprung mass $m_{1}$, the unsprung mass $m_{2}$, and the mass of the air $m_{a}$ are expressed by the following equations:

$m_{1} \ddot{z}_{1}=F_{C}+F_{K e}+F_{K v}+F_{S}+F_{A}$

$m_{2} \ddot{z}_{2}=F_{K T}-F_{C}-F_{K e}-F_{C a}-F_{A}$

$m_{a} \ddot{z}_{a}=F_{C a}-F_{K v}$

Where:

Pneumatic force:

$F_{S}=p_{b} A_{e}=p_{0}\left[\left(\frac{V_{b 0}}{V_{b 0}-A_{e}\left(z_{2}-z_{1}\right)}\right)^{n}-1\right] A_{e}$

Linear damping force:

$F_{C}=C\left(\dot{z}_{2}-\dot{z}_{1}\right)$

Main spring force:

$F_{K e}=K_{e}\left(z_{2}-z_{1}\right)$

Auxiliary spring force:

$F_{K v}=K_{v}\left(z_{a}-z_{1}\right)$ 
Nonlinear damping force:

$F_{C a}=C_{a}\left(\dot{z}_{2}-\dot{z}_{a}\right)^{2}$

Tire force:

$F_{K T}=K_{T}\left(h-z_{2}\right)$

The value of force $F_{A}$ that is generated from the controller needs to be calculated through the control model.

\subsection{Control model}

Different from other common research which only uses pneumatic springs in the suspension system, this research has integrated the hydraulic actuator with the pneumatic suspension system. When the vehicle's body oscillates, the hydraulic actuator will generate a force $F_{A}$ acting on the sprung mass $m_{1}$ and the unsprung mass $m_{2}$. The actuator is automatically controlled through the previously established controller (Figure 4).

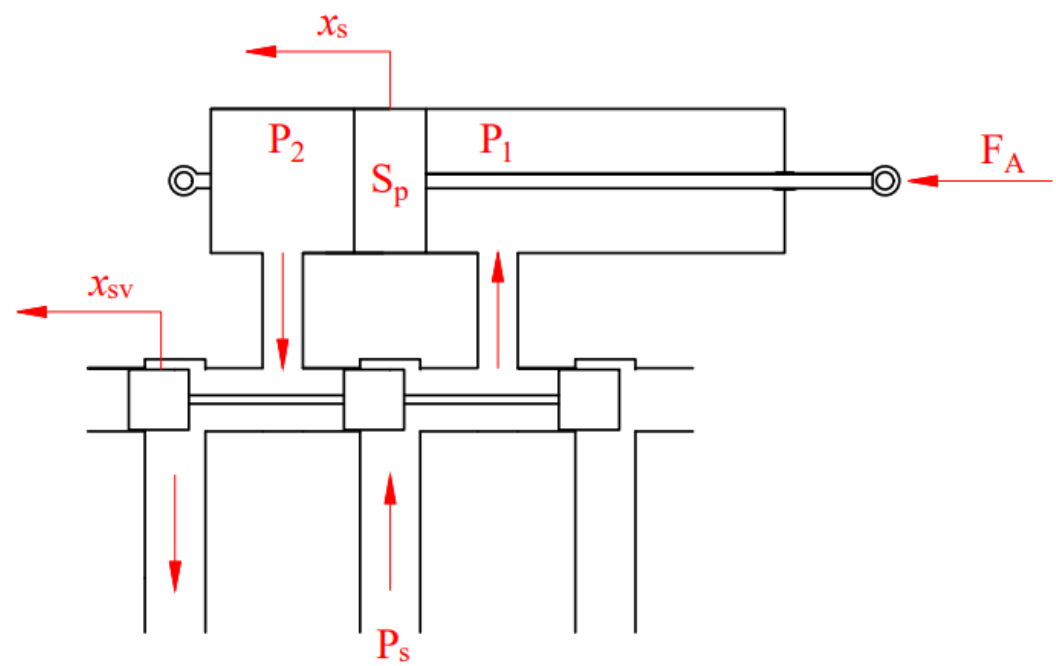

Figure 4 The hydraulic actuator.

The actuator force $F_{A}$ depends on the change in hydraulic pressure inside the system:

$F_{A}=S_{p} \Delta P$

The difference in hydraulic pressure inside the actuator is expressed through the piston's displacement and liquid's flow:

$$
\begin{aligned}
& \Delta P=\gamma_{1} \int\left(Q-\frac{\gamma_{2}}{\gamma_{1}} P-S_{p} \dot{x}_{s}\right) d t \\
& Q=\frac{\gamma_{3}}{\gamma_{1}} x_{s v} \sqrt{P_{s}-\operatorname{sgn}\left(x_{s v}\right) \Delta P}
\end{aligned}
$$

The flow of liquid through the valve depends on the opening and closing of the valve. The valves are opened and closed by the control voltage signal $\mathrm{u}(\mathrm{t})$, which is generated from the controller. 
$x_{s v}=\frac{1}{\tau} \int\left(k_{s v} u(t)-x_{s v}\right) d t$

Where: : Actuator coefficient

$\tau$ : Time coefficient

$\mathrm{S}_{\mathrm{p}}$ : Piston cross section

$\mathrm{k}_{\mathrm{sv}}$ : Servo valve gain

$\mathrm{x}_{\mathrm{sv}}$ : Displacement of the servo valve

This paper uses the PI controller to control the operation of the hydraulic actuator. Compared with other controllers, the $\mathrm{PI}$ controller has many advantages such as low cost, high reliability, easy control. Besides, this controller works stably with the SISO control object.

Although the established dynamics model has three degrees of freedom, the control object here is only the acceleration of the sprung mass. When the acceleration of the sprung mass is controlled, the value of displacement of the sprung mass can also be improved. Therefore, it is perfectly appropriate to use a PI controller.

The PID controller consists of three stages: Proportional (P), Integral (I), and Derivative (D). The mathematical model of this controller is given as (20). If the Derivative stage $(D)$ is eliminated $\left(T_{D}=0\right)$, it becomes a PI controller, which consists of only two stages.

$$
u(t)=k_{p}\left[e(t)+\frac{1}{T_{I}} \int_{0}^{t} e(\tau) d \tau+T_{D} \dot{e}(t)\right]
$$

Where:

$\mathrm{e}(\mathrm{t})$ : input signal of the controller.

$u(t)$ : output signal of the controller.

$\mathrm{k}_{\mathrm{p}}$ : proportional coefficient.

$T_{1}$ : integral coefficient.

$T_{D}$ : derivative coefficient.

There are many methods used to determine the parameters of the PI controller. In this paper, the controller's parameters are determined by the second Ziegler-Nichols method [46]. The transfer function of the controller is given as (21).

$R(s)=k_{p}\left(1+\frac{1}{T_{I} s}\right)=\delta k_{t h}\left(1+\frac{1}{\lambda T_{t h} s}\right)$

\section{RESULTS AND DISCUSSIONS}

\subsection{Simulation conditions}

After the vehicle dynamics model has been established, simulation is done. The specifications of the vehicle and hydraulic actuator are given in Tables 1 and 2 respectively [47].

Table 1 The specifications of the vehicle.

\begin{tabular}{cccc}
\hline Symbol & Description & Value & Unit \\
\hline $\mathrm{m}_{1}$ & Sprung mass & 400 & $\mathrm{~kg}$ \\
$\mathrm{~m}_{2}$ & Unsprung mass & 40 & $\mathrm{~kg}$ \\
$\mathrm{C}$ & Damper coefficient & 3000 & $\mathrm{Ns} / \mathrm{m}$ \\
$\mathrm{K}_{\mathrm{T}}$ & Tire coefficient & 180000 & $\mathrm{~N} / \mathrm{m}$ \\
\hline
\end{tabular}


Table 2 The specifications of the hydraulic actuator.

\begin{tabular}{|c|c|c|c|}
\hline Symbol & Description & Value & Unit \\
\hline$A_{e}$ & Effective area of the pneumatic spring & 0.002 & $\mathrm{~m}^{2}$ \\
\hline$A_{s}$ & Connecting pipe cross section & $3 \times 10^{-4}$ & $\mathrm{~m}^{2}$ \\
\hline$I_{s}$ & Connecting pipe length & 2 & $\mathrm{~m}$ \\
\hline$p_{\text {at }}$ & Atmospheric pressure & $1 \times 10^{5}$ & $\mathrm{~N} / \mathrm{m}^{2}$ \\
\hline$p_{0}$ & Initial absolute pneumatic spring pressure & $4 \times 10^{5}$ & $\mathrm{~N} / \mathrm{m}^{2}$ \\
\hline $\mathrm{V}_{\mathrm{r} 0}$ & Initial volumes of the reservoir & 0.004 & $\mathrm{~m}^{3}$ \\
\hline $\mathrm{V}_{\mathrm{b} 0}$ & Initial volumes of the balloon & 0.008 & $m^{3}$ \\
\hline$\rho$ & Density of the air at initial condition & 1.29 & $\mathrm{~kg} / \mathrm{m}^{3}$ \\
\hline$\beta$ & Constant & 2 & \\
\hline k & Total loss coefficient of the connection pipes & 3.5 & \\
\hline $\mathrm{n}$ & Multivariable coefficient & 1.4 & \\
\hline$\gamma_{1}$ & Actuator coefficient & $4.5 \times 10^{13}$ & $\mathrm{~N} / \mathrm{m}^{5}$ \\
\hline$\gamma_{2}$ & Actuator coefficient & 1 & $\mathrm{~s}^{-1}$ \\
\hline$\gamma_{3}$ & Actuator coefficient & $1.5 \times 10^{9}$ & $\mathrm{~N} / \mathrm{kg}^{1 / 2} \mathrm{~m}^{5 / 2}$ \\
\hline$\tau$ & Time coefficient & $2.5 \times 10^{-3}$ & s \\
\hline $\mathrm{S}_{\mathrm{p}}$ & Piston cross section & $3.5 \times 10^{-4}$ & $\mathrm{~m}^{2}$ \\
\hline $\mathrm{P}_{\mathrm{s}}$ & Supply pressure & 1056240 & $\mathrm{~N} / \mathrm{m}^{2}$ \\
\hline $\mathrm{k}_{\mathrm{sv}}$ & Servo valve gain & $1 \times 10^{-3}$ & $\mathrm{~m} / \mathrm{V}$ \\
\hline
\end{tabular}

The results of the simulation process are the displacement of the sprung mass, the acceleration of the sprung mass, and the change in pressure of the pneumatic suspension. These are the parameters that characterize the vehicle's oscillation. The maximum value and changing trend of these parameters are interesting objects. Besides, the average value is also calculated to be able to determine the stable oscillation threshold of the system. The average value of the oscillation is calculated by the Root Mean Square method (RMS).

$$
R M S=\sqrt{\frac{1}{n} \sum_{i=1}^{n} x_{i}^{2}}
$$

Stimulation from the road surface is a factor that directly affects the smoothness and comfort of the vehicle. In this paper, three types of the excitation are used, including sine wave, random, and step. The values of displacement of the sprung mass and the acceleration of the sprung mass will be determined corresponding to the simulation cases, including:

+ Vehicles using passive suspension system $(\mathrm{Pa})$

+ Vehicles using conventional pneumatic suspension system (Pn)

+ Vehicles using integrated pneumatic suspension system (I-Pn) 


\subsection{Results}

\section{Case 1: Sine wave type}

In this case, the excitation from the road surface takes the form of a periodic sine wave function. This type is often used in control problems. The graph in Figure 5 shows the change of displacement of the sprung mass over time. If the vehicle uses only the conventional passive suspension system, the value of the displacement of the sprung mass is quite large, reaching about $50.10(\mathrm{~mm})$. Its trajectory closely matches that of the excitation signal from the road surface. When the vehicle uses the pneumatic suspension system, this value may decrease. However, the change is small. If the vehicle is equipped with a pneumatic suspension system integrated with the hydraulic actuator, the displacement value of the sprung mass is significantly reduced. The maximum amplitude of vibration is only about $27.55(\mathrm{~mm})$, it is much smaller than the two cases mentioned above. According to equation (22), the mean value of oscillation in this case reaches $\mathrm{RMS}_{\mathrm{pa}}$

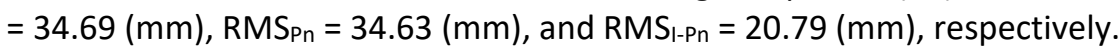

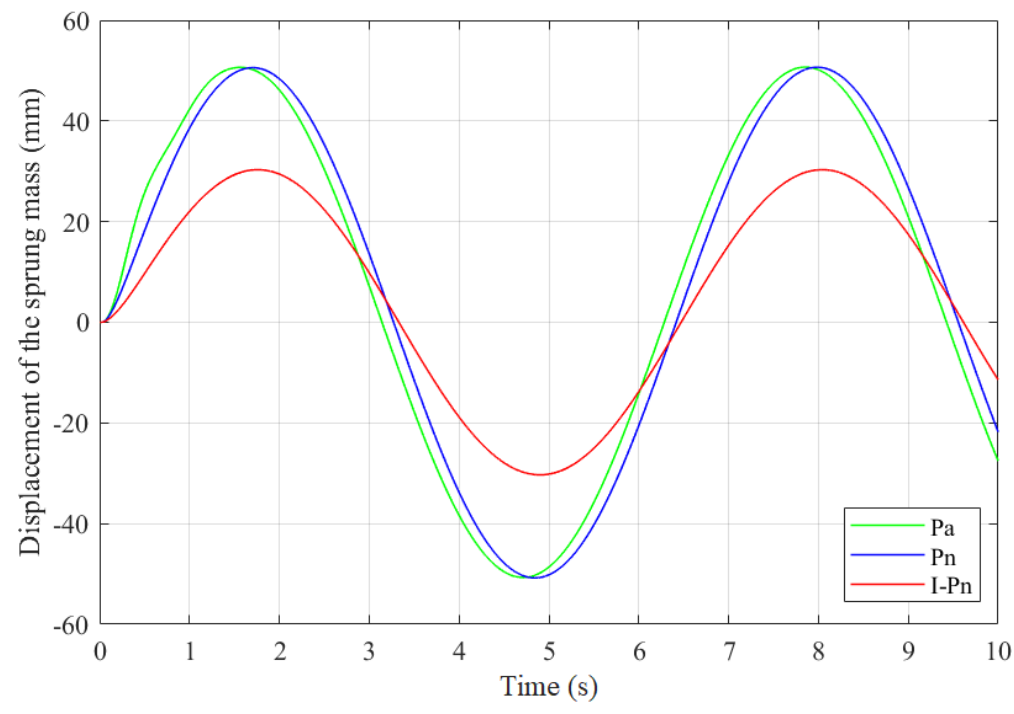

Figure 5 Displacement of the sprung mass.

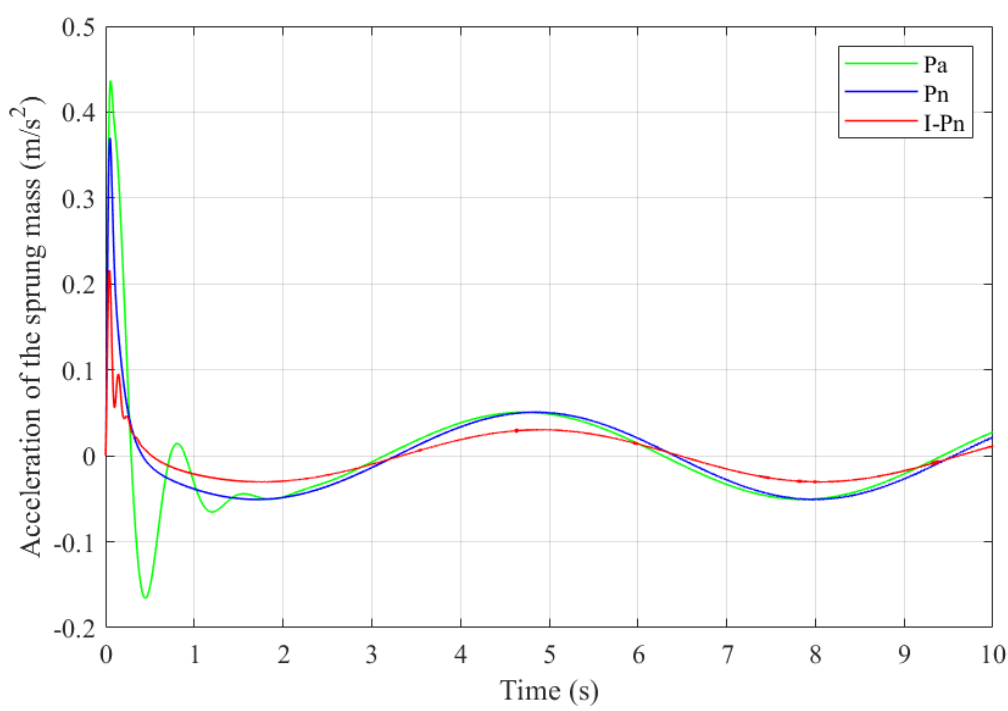

Figure 6 Acceleration of the sprung mass.

Acceleration of the sprung mass is a characteristic parameter for the smoothness and comfort of the vehicle when moving on the road. Figure 6 shows the change of this value in the case of excitation from the road surface having a sine form. If the vehicle uses only the passive suspension system, the maximum value of acceleration is quite large, reaching about $0.44\left(\mathrm{~m} / \mathrm{s}^{2}\right)$. This value tends to decrease gradually and fluctuates stably around the threshold of $0.05\left(\mathrm{~m} / \mathrm{s}^{2}\right)$. When the pneumatic suspension system is used to replace the passive suspension system, the change of this value is also not much. Therefore, the smoothness and comfort of the vehicle cannot be improved. If the pneumatic suspension system 
is integrated with a hydraulic actuator, the vehicle's stability and comfort can be further improved. Its maximum value reaches $0.22\left(\mathrm{~m} / \mathrm{s}^{2}\right)$, only half that of the vehicle using the passive suspension system. After reaching the maximum value, its amplitude of oscillation gradually decreases. The value fluctuates steadily between $-0.023\left(\mathrm{~m} / \mathrm{s}^{2}\right)$ to $0.023\left(\mathrm{~m} / \mathrm{s}^{2}\right)$. Besides, the average value of acceleration in this case is $\mathrm{RMS}_{\mathrm{Pa}_{a}}=0.052\left(\mathrm{~m} / \mathrm{s}^{2}\right), \mathrm{RMS}_{\mathrm{P}_{n}}=0.043\left(\mathrm{~m} / \mathrm{s}^{2}\right)$, and RMS $1-\mathrm{Pn}_{n}=0.025$ $\left(\mathrm{m} / \mathrm{s}^{2}\right)$, respectively. In general, if the vehicle is equipped with an integrated pneumatic suspension system, the vehicle's stability and comfort can be significantly improved.

The pressure of the pneumatic suspension system changes continuously depending on the stimulus from the road surface. This change is shown graphically in Figure 7. The change in pressure when the vehicle is equipped with an integrated pneumatic suspension system is larger than when the vehicle is used with the conventional pneumatic suspension system, this is a perfect fit. The pressure in the system can change continuously in response to the fluctuations of the stimuli from the road surface.

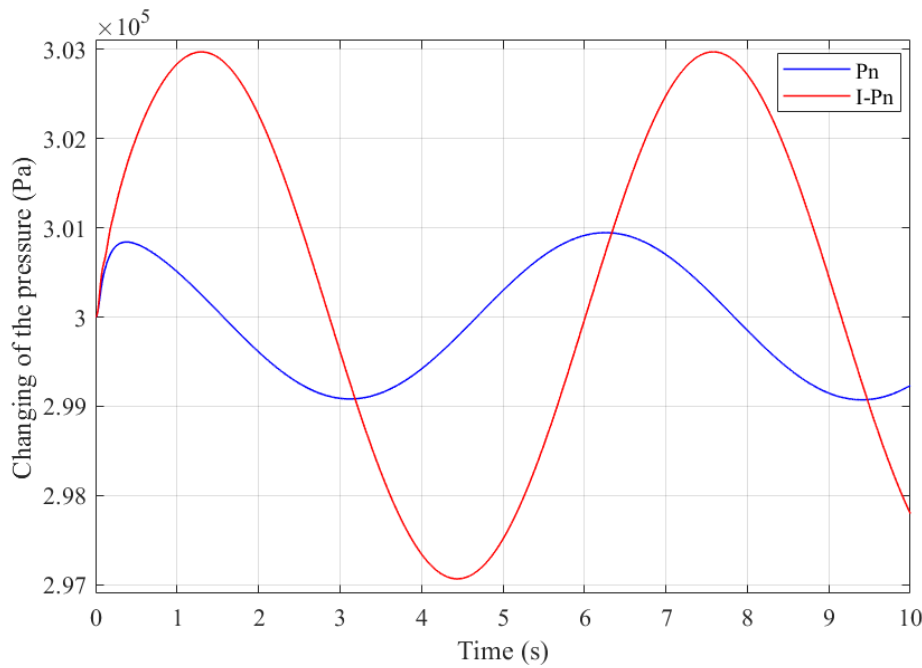

Figure 7 Changing of the pressure of the pneumatic spring.

\section{Case 2: Random type}

In this case, random excitation is used. This is the actual pavement type, and it gives more accurate results than the sine form. In Figure 8, the change of displacement of the sprung mass over time is clearly shown. This value changes continuously, and it does not follow any rules because the excitation from the road surface is random. Although the maximum amplitude of the stimulus from the road surface is only $50.00(\mathrm{~mm})$, the displacement value can reach 70.12 $(\mathrm{mm})$ and $39.70(\mathrm{~mm})$ respectively in the case of the vehicle using the passive suspension system and the conventional pneumatic suspension system. If the integrated pneumatic suspension system is equipped, this value is further reduced. Besides, the difference in displacement at different times is not large. The average value of vehicle body's displacement in this case, respectively, reaches RMS $=\{30.70 ; 17.06 ; 12.56\}(\mathrm{mm})$.

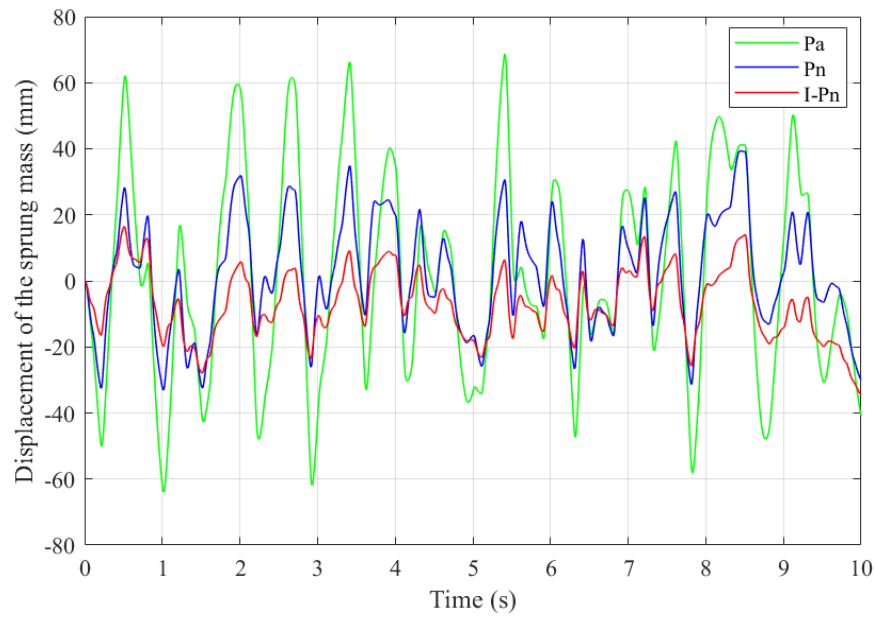

Figure 8 Displacement of the sprung mass. 


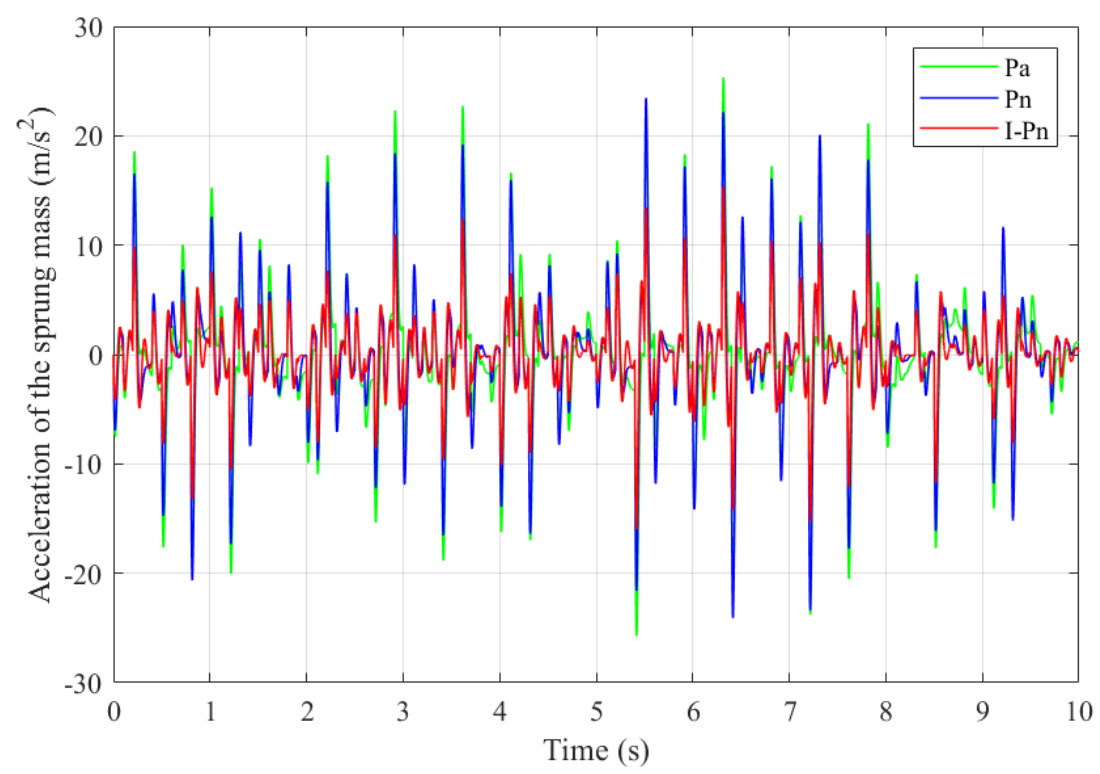

Figure 9 Acceleration of the sprung mass.

The acceleration of the vehicle body in this case fluctuates continuously (Figure 9). Besides, its maximum value is also very large, can reach $25.51\left(\mathrm{~m} / \mathrm{s}^{2}\right)$ if the vehicle only uses the passive suspension system. This is a huge value, and it can affect the smoothness and comfort of the vehicle. If the vehicle uses the conventional pneumatic suspension system, the maximum value of acceleration can reach $23.12\left(\mathrm{~m} / \mathrm{s}^{2}\right)$, the difference is not too large. Otherwise, if the integrated pneumatic suspension system is equipped to replace the other suspension systems, stability and comfort can be further improved. The maximum value of the acceleration of the sprung mass, in this case, is only $15.72\left(\mathrm{~m} / \mathrm{s}^{2}\right)$, which is much smaller than the other two cases. This stability is also shown through the average value of acceleration $\mathrm{RMS}_{\mathrm{Pa}}=6.53$ $\left(\mathrm{m} / \mathrm{s}^{2}\right), \mathrm{RMS}_{\mathrm{Pn}_{n}}=6.18\left(\mathrm{~m} / \mathrm{s}^{2}\right)$, and $\mathrm{RMS}_{\mathrm{I}-\mathrm{Pn}}=3.78\left(\mathrm{~m} / \mathrm{s}^{2}\right)$.

To be able to respond well to changes from road surface stimuli, the pressure of the pneumatic suspension system needs to be constantly changing. The change in pneumatic pressure when the vehicle uses the integrated pneumatic suspension system is better and more consistent than with the conventional pneumatic suspension system (Figure 10). As a result, stability and safety issues of the vehicle can be more assured.

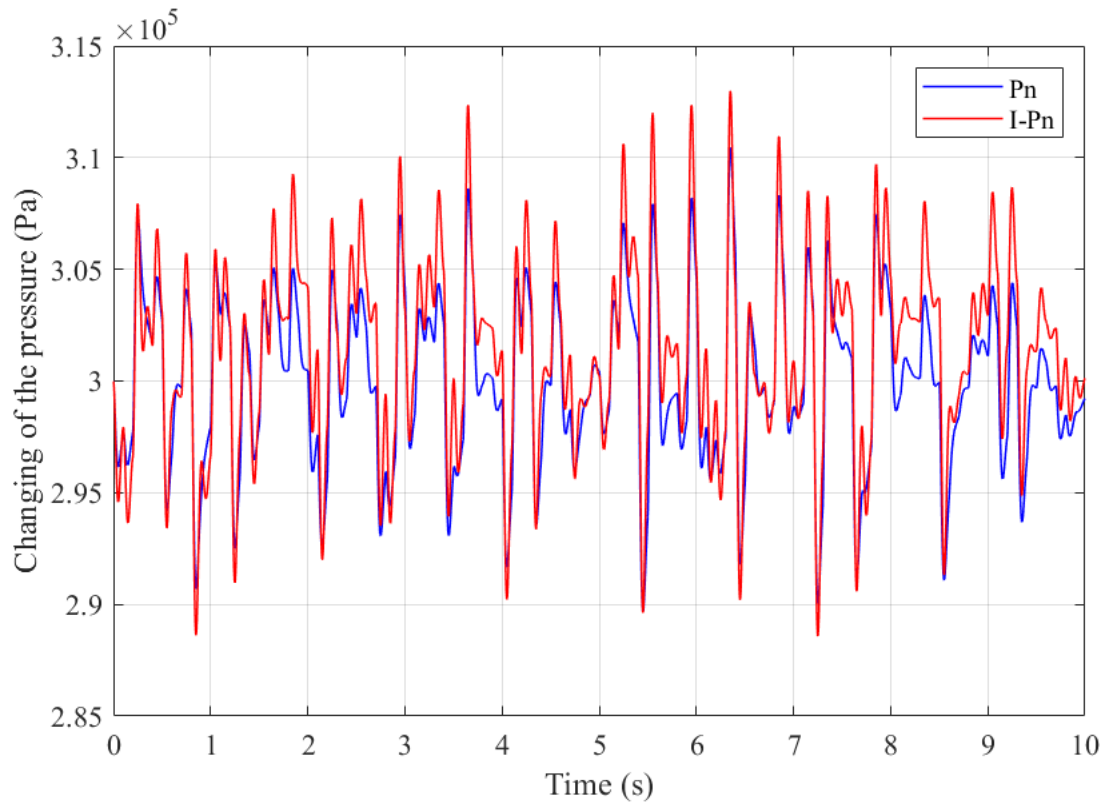

Figure 10 Changing of the pressure of the pneumatic spring. 
Case 3: Step type

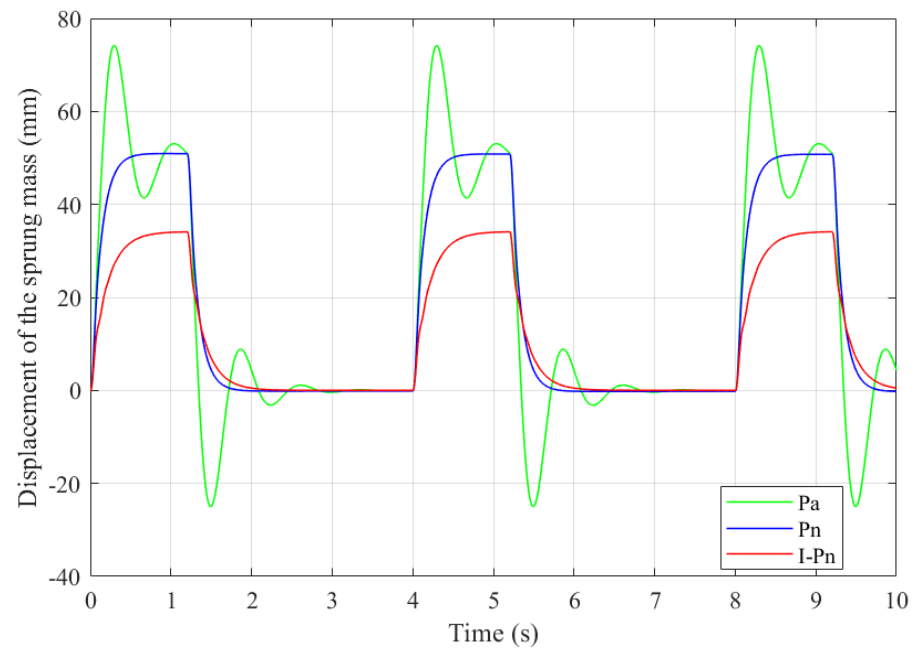

Figure 11 Displacement of the sprung mass.

Step stimulation is used in this case. The displacement of the sprung mass was markedly different in the three simulation conditions (Figure 11). The maximum value of amplitude reached 73.42 ( $\mathrm{mm}), 49.53$ (mm), and 32.82 (mm) respectively. The acceleration of the sprung mass is also significantly different when the vehicle uses the integrated pneumatic suspension system (Figure 12). Its maximum value is only about $57.3 \%$ compared to the vehicle using the passive suspension system. The pneumatic pressure variation of the suspension system is suitable, which response well to changes from external stimuli (Figure 13).

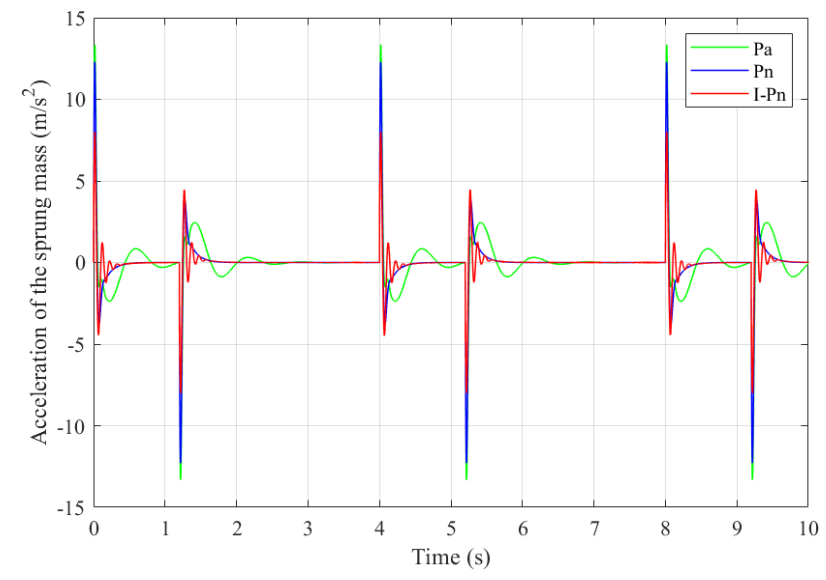

Figure 12 Acceleration of the sprung mass.

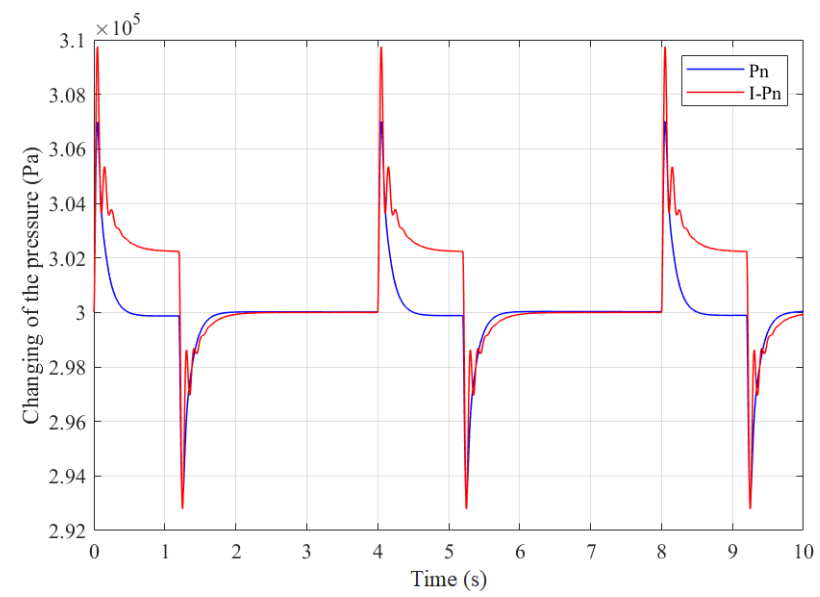

Figure 13 Changing of the pressure of the pneumatic spring. 
In general, when the vehicle was equipped with the pneumatic suspension system that integrated the hydraulic actuator, the displacement and acceleration values of the sprung mass were significantly reduced compared with the other two cases. This has been demonstrated through various excitation conditions from the road surface. Therefore, the smoothness and comfort of the vehicle have been greatly improved. The results of the simulation process are shown in Tables 3 and 4.

Table 3 The maximum value of the oscillation.

\begin{tabular}{|c|c|c|c|c|c|c|}
\hline & \multicolumn{2}{|c|}{$\mathrm{Pa}$} & \multicolumn{2}{|c|}{ Pn } & \multicolumn{2}{|c|}{ I-Pn } \\
\hline & Dis (mm) & $\operatorname{Acc}\left(\mathrm{m} / \mathrm{s}^{2}\right)$ & Dis (mm) & $\operatorname{Acc}\left(\mathrm{m} / \mathrm{s}^{2}\right)$ & Dis $(\mathrm{mm})$ & $\operatorname{Acc}\left(\mathrm{m} / \mathrm{s}^{2}\right)$ \\
\hline Case 1 & 50.10 & 0.44 & 49.91 & 0.37 & 27.55 & 0.22 \\
\hline Case 2 & 70.12 & 25.51 & 39.70 & 23.12 & 26.31 & 15.72 \\
\hline Case 3 & 73.42 & 13.63 & 49.53 & 12.52 & 32.82 & 7.81 \\
\hline
\end{tabular}

Table 4 The average value of the oscillation.

\begin{tabular}{|c|c|c|c|c|c|c|}
\hline & \multicolumn{2}{|c|}{$\mathrm{Pa}$} & \multicolumn{2}{|c|}{ Pn } & \multicolumn{2}{|c|}{ I-Pn } \\
\hline & Dis (mm) & $\operatorname{Acc}\left(m / s^{2}\right)$ & Dis $(\mathrm{mm})$ & $\operatorname{Acc}\left(\mathrm{m} / \mathrm{s}^{2}\right)$ & Dis $(\mathrm{mm})$ & $\operatorname{Acc}\left(\mathrm{m} / \mathrm{s}^{2}\right)$ \\
\hline Case 1 & 34.69 & 0.052 & 34.63 & 0.043 & 20.79 & 0.025 \\
\hline Case 2 & 30.70 & 6.53 & 17.06 & 6.18 & 12.56 & 3.78 \\
\hline Case 3 & 32.30 & 2.40 & 28.89 & 2.15 & 18.83 & 1.46 \\
\hline
\end{tabular}

\section{NOMENCLATURE}

$\mathrm{F}_{\mathrm{A}}$ : Actuator force, $\mathrm{N}$

$\mathrm{F}_{\mathrm{C}}$ : Linear damping force, $\mathrm{N}$

$\mathrm{F}_{\mathrm{Ca}}$ : Nonlinear damping force, $\mathrm{N}$

$F_{f}$ : Friction force, $N$

$F_{K e}$ : Main spring force, $N$

$\mathrm{F}_{\mathrm{KV}}$ : Auxiliary spring force, $\mathrm{N}$

$F_{p}$ : Push force, $N$

$F_{S}$ : Pneumatic force, $N$

$\mathrm{F}_{\mathrm{z}}$ : Static force, $\mathrm{N}$

$\mathrm{h}$ : Bump on the road, $\mathrm{m}$

$\mathrm{m}_{1}$ : Sprung mass, $\mathrm{kg}$

$\mathrm{m}_{2}$ : Unsprung mass, $\mathrm{kg}$

$\mathrm{m}_{\mathrm{a}}$ : Pneumatic mass, $\mathrm{kg}$

$z_{1}$ : Displacement of the sprung mass, $m$

$\mathrm{z}_{2}$ : Displacement of the unsprung mass, $\mathrm{m}$

$\mathrm{z}_{\mathrm{a}}$ : Displacement of the pneumatic mass, $\mathrm{m}$

\section{CONCLUSION}

Stability and comfort are very important issues of the vehicle when moving on the road. It directly affects passengers, cargoes, and the durability of the vehicle. The comfort and smoothness are expressed through the vibrations of the sprung mass. Characterizing the main oscillations are the values of displacement and acceleration of the sprung mass (maximum amplitude, stability amplitude, oscillation frequency, etc.). The vehicle's suspension system has the role of regulating and extinguishing the oscillations generated from external stimuli.

In order to improve the efficiency of the suspension system, the stiffness of the spring and damper needs to be changed continuously. The method of equipping the conventional pneumatic suspension system to replace the passive suspension system has been proposed and used. However, the results it brings are still not great. This paper has introduced a method of using the pneumatic suspension system integrated with the hydraulic actuator instead of just using the conventional pneumatic suspension system. The hydraulic actuator is controlled through the established linear controller. Based on the basic parameters of the system, the simulation process was performed for different excitation conditions from the road surface. The results of the research show that when the vehicle is equipped with the integrated 
pneumatic suspension system, the values of displacement and acceleration of the sprung mass are greatly reduced compared to the other two cases. To be able to do this, the system's compressed pneumatic pressure changes are continuous.

The method of using the integrated pneumatic suspension system is completely novel. Its results are also very positive. However, the investment cost is quite expensive. In the future, nonlinear control and intelligent control methods can be used to control this system to improve its efficiency. Besides, the experimental process is necessary to be able to demonstrate the effectiveness of the integrated pneumatic suspension system.

Editor: Marcílio Alves.

\section{References}

[1] Yin, J., Chen, X., Li, J., and Wu, L. (2015). Investigation of Equivalent Unsprung Mass and Nonlinear Features of Electromagnetic Actuated Active Suspension, Shock and Vibration.

[2] Basargan, H., Mihaly, A., Gaspar, P., and Sename, O. (2021). Adaptive Semi-Active Suspension and Cruise Control through LPV Technique, Applied Sciences 11(1).

[3] Pang, H., Fu, W., and Liu, K. (2015). Stability Analysis and Fuzzy Smith Compensation Control for Semi-active Suspension Systems with Time Delay, Journal of Intelligent \& Fuzzy Systems 29(6): 2513-25.

[4] Melo, F. J. M. Q., Pereira, A. B., and Morais, A. B. (2018). The Simulation of an Automotive Air Spring Suspension Using a Pseudo-dynamic Procedure, Applied Sciences 8(7).

[5] Alonso, A., Gimenez, J. G., Nieto, J., and Vinolas, J. (2010). Air Suspension Characterisation and Effectiveness of a Variable Area Orifice, Vehicle System Dynamics 48: 271-86.

[6] Yin, Z., Khajepour, A., Cao, D., Ebrahimi, B., and Guo, K. (2012). A New Pneumatic Suspension System with Independent Stiffness and Ride Height Tuning Capabilities, Vehicle System Dynamic 50(12): 1735-46.

[7] Eskandary, P. K., Khajepour, A., Wong, A., and Ansari, M. (2016). Analysis and Optimization of Air Suspension System with Independent Height and Stiffness Tuning, International Journal of Automotive Technology 17(5): 807-16.

[8] Abid H. J., Chen J., and Nassar, A. A. (2015). Equivalent Air Spring Suspension Model for Quarter Passive Model of Passenger Vehicles, International Scholarly Research Notices.

[9] Gavriloski, V., Jovanova, J., Tasevski, G., and Djidrov, M. (2014). Development of a New Air Spring Dynamic Model, FME Transactions 42(4): 305-10.

[10] Moheyeldein, M. M., Tawwab, A. M. A. E., Elgwwad, K. A. A., and Salem, M. M. M. (2018). An Analytical Study of the Performance Indices of Air Spring Suspension Over the Passive Suspension, Beni-Suef University Journal of Basic and Applied Sciences 7: 525-34.

[11] Zhu, H., Yang, J., Zhang, Y., Feng, X., and Ma, Z. (2017). Nonlinear Dynamic Model of Air Spring with a Damper for Vehicle Ride Comfort, Nonlinear Dynamics 89: 1545-68.

[12] Xiao, P., Gao, H., Shi, P., and Niu, L. (2018). Research on Air Suspension with Novel Dampers Based on Glowworm Swarm Optimization Proportional Integral Derivative Algorithm, Advances in Mechanical Engineering 10(8).

[13] Li, Z., Song, X., Chen, X., and Xue, H. (2021). Dynamic Characteristics Analysis of the Hub Direct Drive Air Suspension System from Vertical and Longitudinal Directions, Shock and Vibration.

[14] Ikrama, K., et al. (2020). Development of Active Air Suspension System for Small Agricultural Vehicles, Big Data in Agriculture 2(2): 23-28.

[15] Genovese, A., Strano, S., and Terzo, M. (2020). Design and Multi-physics Optimization of an Energy Harvesting System Integrated in a Pneumatic Suspension, Mechatronics 69.

[16] Kwon, K., Seo, M., Kim, H., Lee, T., Lee, J., and Min, S. (2020). Multi-objective Optimisation of Hydro-pneumatic Suspension with Gas-online Emulsion for Heavy-duty Vehicles, Vehicle System Dynamics 58(7): 1146-65.

[17] Jiao, R., Nguyen, V., and Le, V. (2020). Ride Comfort Performance of Hydro Pneumatic Isolation for Soil Compactors Cab in Low Frequency Region, Journal of Vibroengineering 22(5): 1174-86. 
[18] Qin, B., Zeng, R., Li, X., and Yang, J. (2021). Design and Performance Analysis of the Hydropneumatic Suspension System for a Novel Road-rail Vehicle, Applied Sciences 11(5).

[19] Garcia, I. M., Laborda, N. G., Mallabiabarrena, A. P., and Berg, M. (2020). A Survey on the Modelling of Air Spring Secondary Suspension in Railway Vehicles, Vehicle System Dynamics.

[20] Le, V. Q. (2017). Comparing the Performance of Suspension System of Semi-trailer Truck with Two Air Suspension Systems, Journal of Vibroengineering 14: 220-26.

[21] Kumbhar, M. B., Salunkhe, V. G., Borgaonkar, A. V., and Jagadeesha, T. (2020). Mathematical Modeling and Experimental Evaluation of an Air Spring-Air Damper Dynamic Vibration Absorber, Journal of Vibration Engineering \& Technologies.

[22] Anh, N. T. (2020). Control an Active Suspension System by Using PID and LQR Controller, International Journal of Mechanical and Production Engineering Research and Development 10(3): 7003-12.

[23] Pang, H., Chen, Y., Chen, J., and Liu, X. (2017). Design of LQG Controller for Active Suspension without Considering Road Input Signals, Shock and Vibration.

[24] Zhao, R., Xie, W., Wong, P. K., Cabecinhas D., and Silvestre, C. (2019). Robust Ride Height Control for Active Air Suspension Systems with Multiple Unmodeled Dynamics and Parametric Uncertainties, IEEE Access, 7: 59185-199.

[25] Kaleemullah, M., Faris, W. F., and Ghazaly, N. M. (2019). Analysis of Active Suspension Control Policies for Vehicle Using Robust Controllers, International Journal of Advances Science and Technology 28(16): 836-855.

[26] Rizvi, S. M. H., Abid, M., Khan, A. Q., Satti, S. G., and Latif, J. (2018). Hळ Control of 8 Degrees of Freedom Vehicle Active Suspension System, Journal of King Saud University - Engineering Sciences 30(2) 161-69.

[27] Nieto, A. J., Morales, A. L., Chicharro, J. M., and Pintado, P. (2016). An Adaptive Pneumatic Suspension System for Improving Ride Comfort and Handling, Journal of Vibration and Control 22(6): 1492-503.

[28] Fu, Z. J., Li, B., Ning, X. B., and Xie, W. D. (2017). Online Adaptive Optimal Control of Vehicle Active Suspension System Using Signal-network Approximate Dynamic Programming, Mathematical Problems in Engineering.

[29] Rui, B. (2019). Nonlinear Adaptive Sliding Mode Control of the Electronically Controlled Air Suspension System, International Journal of Advanced Robotic Systems.

[30] Zhao, R., Xie, W., Zhao, J., Wong, P. K., and Silvestre, C. (2021). Nonlinear Ride Height Control of Active Air Suspension System with Output Constraints and Time-varying Disturbances, Sensors 21(4).

[31] Sun, X., Yuan, C., Cai, Y., Wang, S., and Chen, L. (2017). Model Predictive Control of an Air Suspension System with Damping Multimode Switching Damper Based on Hybrid Model, Mechanical Systems and Signal Processing 94: 94-110.

[32] Chen, Y., Zhang, S., Mao, E., Du, Y., Chen, J., and Yang, S. (2020). Height Stability Control of a Large Sprayer Body Based on Air Suspension Using the Sliding Mode Approach, Information Processing in Agriculture 7(1): 20-9.

[33] Zhou, C., Liu, X., Xu, F., and Chen, W. (2020). Sliding Mode Switch Control of Adjustable Hydro-pneumatic Suspension Based on Parallel Adaptive Clonal Selection Algorithm, Applied Sciences 10(5).

[34] Li, H., Li, S., Sun, W., Wang, L., and Lv, D. (2020). The Optimum Matching Control and Dynamic Analysis for Air Suspension of Multi-axle Vehicles with Anti-roll Hydraulically Interconnected System, Mechanical Systems and Signal Processing: 139.

[35] Soleymani, M., Montazeri-Gh, M., and Amiryan, R. (2012). Adaptive Fuzzy Controller for Vehicle Active Suspension System Based on Traffic Conditions, Scientia Iranica 19(3): 443-53.

[36] Na, J., Huang, Y., Wu, X., Su, S. F., and Li, G. (2020). Adaptive Finite-time Fuzzy Control of Nonlinear Active Suspension Systems with Input Delay, IEEE Transaction Cybernetics 50(6): 2639-50.

[37] Lin, B., Su, X., and Li, X. (2019). Fuzzy Sliding Mode Control for Active Suspension System with Proportional Differential Sliding Mode Observer, Asian Journal of Control 21(1).

[38] Palanisamy, S., and Karuppan, S. (2016). Fuzzy Control of Active Suspension System, Journal of Vibroengineering 18(5): 3197-204.

[39] Lin, J., Lian, R. J., Huang, C. N., and Sie, W. T. (2009). Enhanced Fuzzy Sliding Mode Controller for Active Suspension Systems, Mechatronics 19(7): 1178-90. 
[40] Tamburrano, P., Plummer, A. R., Distaso, E., and Amirante, R. (2019). A Review of Electro-hydraulic Servo-valve Research and Development, International Journal of Fluid Power 20(1): 53-98.

[41] Lee, J. Oh, K., and Yi, K. (2020). A Novel Approach to Design and Control of an Active Suspension Using Linear Pump Control-based Hydraulic System, Journal of Automobile Engineering 234(5): 1224-48.

[42] Shafie, A. A., Bello, M. M., and Khan, R. M. (2015). Active Vehicle Suspension Control Using Electro Hydraulic Actuator on Rough Road Terrain, Journal of Advances Research in Applied Mechanics 9(1): 15-30.

[43] Bai, R., and Guo, D. (2018). Sliding-mode Control of the Active Suspension System with the Dynamics of a Hydraulic Actuator, Complexity.

[44] Sam, Y. M., and Osman, J. H. S. (2006). Sliding Mode Control of a Hydraulically Actuated Active Suspension, Jurnal Teknologi 44: 37-48.

[45] Sam, Y. M., Hudha, K., and Osman, J. H. S. (2007). Proportional-integral Sliding Mode Control of a Hydraulically Actuated Active Suspension System: Force Tracking and Disturbance Rejection Control on Non-linear Quarter Car Model, International Journal of Vehicle Systems Modelling and Testing 2(4): 391-410.

[46] Patel, V. V. (2020). Ziegler-Nichols Tuning Method, Resonance 25: 1385-97.

[47] Nguyen, T. A. (2021). Improving the Comfort of the Vehicle Based on Using the Active Suspension System Controlled by the Double-Integrated Controller, Shock and Vibration. 